\title{
Research on the Simulation Model of Above-Ground Organs Morphogenesis of Flue-Cured Tobacco
}

\author{
Shuping Xiong ${ }^{1}$, Lei $\mathrm{Xi}^{2}$, Jucai Wang ${ }^{2}$, Guanghui $\mathrm{Xu}^{1,3}$, and Xinming $\mathrm{Ma}^{1,2, *}$ \\ ${ }^{1}$ Agronomy College of Henan Agricultural University, zhengzhou 450002, China \\ ${ }^{2}$ College of Information and Management Science, \\ Henan Agricultural University, zhengzhou 450002, China \\ ${ }^{3}$ Yexian Branch of Pingdingshan Tobacco Company, Yexian 467200, China \\ xinmingma@126.com, shupxiong@163.com
}

\begin{abstract}
In order to create the simulation model of Above-ground Organs Morphogenesis of Flue-cured Tobacco, the dynamic model of organ morphology in different growing step of tobacco was built with potting experimental methods with which the biomass of tobacco organ in different growth period can be systematically determined. As simulation of organ morphology of tobacco measured in 2007 shows that the correlation coefficient between the simulated value and the measured value of above-ground organ of tobacco in different growth cycle is 0.735 to 0.9997 at significant level which proved that the dynamic of above-ground organ morphogenesis of tobacco can be predicted well by the model. The regulation of growth of tobacco morphology can be reflected well by the model of above-ground organ morphogenesis; furthermore, the model can also be a theoretical basis for virtual growth of tobacco.
\end{abstract}

Keywords: Flue-cured Tobacco, above-ground organ, morphogenesis, model of simulation.

With the dynamic development of information technology on agriculture, more and more researches on virtual plant have been taking. The morphogenesis model, a key technology in virtual plants, has aroused our attention. Ulam [1] and Cohen [2] were the pioneers on research to models of plant branches. These were followed by Lindermayer and his L-system [3], basing on the analysis to the plant organ growth, Hunt [4] produced a plant organ-growing model. Besides, de Reffye, a France man, and his assistants developed a plant-growth system, named AMAP [5, 6]. Combining the L-system and computer graphics, A.R. Smith and Prusinkiewicz made the visualization of plant morphology come true [7-10]. Considering the environment model (e.g. Light and disease and pest injury) and measured data from tri-dimension plant on the L-system, virtual plant model was built in the research center CPAI, Australia [11]. The virtual plant system GROGRA2.4 (Growth grammar Interceptor), which was basing on the L-system, was created by Kurth [12].

As a function-structure model, GREENLAB played an important role in the plant structure area [13-15]; it is brief and honest to mechanization. By building Recurrence

* Corresponding author.

D. Li and Y. Chen (Eds.): CCTA 2011, Part III, IFIP AICT 370, pp. 217-229, 2012.

(C) IFIP International Federation for Information Processing 2012 
relations among several Mathematical formulas, the feedback relationship was parallel simulated. It only needed a few certain parameters to simulate the growth of plants like trees. Virtual structure model of plant, like cotton, maize, wheat etc, was produced by de Reffye [16], Zhan Zhigang etc [17], and GREENLAB. Technology frame on shape simulation and tri-demission visualization of corn, basing on growth model, was produced by Zhao Chunjiang etc [19], and it created a new idea and method. After researching the static model on maize canopy structure, Ivanov [20] and Fournier [21] rebuilt the tri-dimension canopy and analyzed the way how the light is used by canopy with the help of oriented-object program, Jin Mingxian [22] built the tri-dimension model for root -growth of maize. Besides, maize- visualization model, produced by Guo Yan and Li Baoguo [23-24], can be used to analyze tri-dimension structure character of maize canopy and the maize canopy space distribution under the effect of morphology. These researches above show that plant simulation has been developing fast in all the areas which it refers.

Tobacco is one of the very important cash crops. Researches about its under-ground organ such as root have been done. Ma Xinming [25-26] once described the dynamic relation between growth of root system and surrounding environment and built a mathematic model on morphological development of tobacco roots. However, researches on above-ground organs of tobacco are rare. Taking the existed researches [27-29] as references, basing on the measured data for building tobacco morphology, researching the dynamic relationship between tobacco morphogenesis regulation and the environment, visualization model about tobacco morphogenesis was built, with the help of morphology module produced by Song Youhong etc [18]. A purpose of this paper is to offer a theory for improving the quality of tobacco and increasing of production.

\section{Material and Methods}

\subsection{Designing of Experiment and Materials in Use}

This experiment was made in the scientific and educational experimental area of Henan Agricultural University during 2006-2007. All the tobacco seeds, seeds K326 in this experiment, were cultivated in the pots, diameter $40 \mathrm{~cm}$, depth $45 \mathrm{~cm}$, filled with sandy and tidal soil. Content of nutrient in the soil were listed as Table1:

Table 1. Content of Nutrient in the Sandy and Tidal Soil

\begin{tabular}{cccccc}
\hline $\begin{array}{c}\text { Index of } \\
\text { Soil }\end{array}$ & $\begin{array}{c}\text { Organic } \\
\text { Matter }\left(\mathrm{g} \cdot \mathrm{kg}^{-1}\right)\end{array}$ & $\begin{array}{c}\text { Available } \\
\mathrm{N}\left(\mathrm{mg} \cdot \mathrm{kg}^{-1}\right)\end{array}$ & $\begin{array}{c}\text { Available } \\
\mathrm{P}\left(\mathrm{mg} \cdot \mathrm{kg}^{-1}\right)\end{array}$ & $\begin{array}{c}\text { Available } \\
\mathrm{K}\left(\mathrm{mg} \cdot \mathrm{kg}^{-1}\right)\end{array}$ & $\mathrm{pH}$ \\
\hline Content & 7.8 & 35 & 9.86 & 80 & 7.6 \\
\hline
\end{tabular}

The weight of soil which should be air-dried and sifted before being used in each pot was $25 \mathrm{~kg}$. Chemical fertilizers used in this soil were $\mathrm{AR}(\mathrm{NH} 4)_{2} \mathrm{SO}_{4}, \mathrm{KNO}_{3}$ and $\mathrm{KH}_{2} \mathrm{PO}_{4}$ and all of these chemical fertilizers should be scattered off as base fertilizer at the first time. The content of fertilizer $\mathrm{N}$ in every kilogram soil was 0.2 gram, and $\mathrm{N}$ : 
$\mathrm{P}_{2} \mathrm{O}_{5}: \mathrm{K}_{2} \mathrm{O}=1: 1.5: 3$. Seeding growing with the float system was cultivated in artificial climatic box in the lab. Sixty days later, they were transplanted into the pot, laid in the soil under the shelter. In this way, the environment where they grow in can be similar with that of farmland. The amount of necessary water in different period of growing for tobacco is varied. The supply of water can be controlled with the help of time-domain reflector (TDR) whose type model is TRIME-FM and shelter should also be open in the raining day to prevent the rainwater in. The management of tobacco, planted in row spacing $1.1 \mathrm{~m}$, plant spacing $0.6 \mathrm{~m}$ in this experiment, has noting different with that of farmland except entering rosette stage in their $30^{\text {th }}$ day and pinching in $57^{\text {th }}$ day after being transplanted.

\subsection{Measured Items and Measuring Methods}

\subsubsection{Measured Items for Internodes: Fresh Weight, Length and Diameter}

Three typical plants from the experimental area should be taken every 10 days after seeding restitution stage. Then, cut them apart by internodes. Fresh weight of internodes can be measured on milli electronic balance. Length of internodes can be measured by ruler which is correct to $0.1 \mathrm{~cm}$. Diameter can be measured by vernier caliper within the accuracy of $0.001 \mathrm{~cm}$.

\subsubsection{The Length, Width and Area of Leaf}

The maximal width on the middle of leaf (Abb. W) and leaf length (Abb. L) can be measured with ruler, and the fresh weight of leaf can be measured with electronic balance. Then, the leaf area (Abb. LA) can be figured out with this formula:

$$
\mathrm{LA}=\mathrm{L} \times \mathrm{W} \times 0.6345
$$

Besides, meteorological data can be achieved from meteorological bureau.

\subsection{Model Testing}

The dynamic model for above-ground organs of tobacco while growing can be built with data measured in 2006 and be tested with the data measured in 2007. The conformity between analog value and observed value can be made a statistical analysis with root mean square error (Abb. RMSE) and 1:1 graphing method. The RMSE can be counted in this equation:

$$
R M S E=\sqrt{\frac{\sum_{i=1}^{n}\left(O B S_{i}-S I M_{i}\right)^{2}}{n}}
$$

OBS: Observed value;

SIM: Analog value;

n: Sample size 


\subsection{Description on Tobacco Models}

\subsubsection{Model on Growth Cycle of Tobacco}

Growth cycle (Abb. GC) was defined as a time span caused by two adjacent me tamers which including internodes, node and leaf growing from the node. It has been proved that the topological structure of plant is obviously affected by cumulative effect which is caused by temperature change of environment [17]. For that growing period of tobacco in field last for 120 130 days which is a pretty long time, the GC was defined as a time unit while modeling. Growing process can be predicted with the following formula (3) which reflect the relationship between tobacco growth and accumulated temperature.

$$
N G C=D R \cdot S u m T+7
$$

NGC: Number of Growth Cycle

DR $\left({ }^{\circ} \mathrm{C}^{-\mathbf{1}}\right)$ : Developing ratio

SumT $\left({ }^{\circ} \mathrm{C}\right)$ : Accumulated temperature which equals to the sum of temperature after being transplanted

The number 7 in formula (3) represented the number of unrolled leaf when the tobacco plant being transplanted, in other words, 7 Growth Cycles has been finished when being transplanted.

\subsubsection{Internodes Morphology of Tobacco}

Growing of tobacco stem can be described in two aspects including prolonging and thickening. Internodes morphology in different position should be built in different way. Leaf 1 to leaf 8, counted from the bottom of stem, are too short to measure when being transplanted. So, they were ignored in this experiment. Only internodes whose position was higher than that of the 8th internode were considered while building morphology.

As the shape of tobacco internode is like a cylinder, volume $\left(\boldsymbol{V}_{\boldsymbol{e}}\right)$ of the internode can be figured out with formula (4):

$$
\mathrm{Ve}(j, i)=\frac{q_{e}(j, i)}{\rho_{e}(j, i)}=l_{e}(j, i) \cdot s_{e}(j, i)
$$

\section{i: Growth cycle (Abb. GC)}

\section{j: Position of internodes}

$\boldsymbol{q}_{\boldsymbol{e}}(\boldsymbol{j}, \boldsymbol{i}):$ Accumulated biomass of the jth internode in its $G C(\mathrm{~g})$.

$\rho_{e}(\boldsymbol{j}, \boldsymbol{i}):$ The internode density $\left(\mathrm{g} / \mathrm{cm}^{-3}\right)$

$\boldsymbol{l}_{\boldsymbol{e}}(\boldsymbol{j}, \boldsymbol{i}):$ The internode length $(\mathrm{cm})$

$\boldsymbol{s}_{\boldsymbol{e}}(\boldsymbol{j}, \boldsymbol{i}):$ Cross-sectional area $\left(\mathrm{cm}^{2}\right)$ 
The length and cross-sectional area of the tobacco internode change with the intercalary growth and primary thickening growth of the internode. Analyzing the experimental data, changing relationship can be built as following:

$$
l_{e}(j, i)=k_{e} \cdot s_{e}(j, i)^{\alpha}
$$

$\boldsymbol{k}_{\boldsymbol{e}}, \alpha$ : Fitting index which is possible to change with the change of the internode position

If defining the morphology index of the internode $\beta$ and $\boldsymbol{b}_{\boldsymbol{e}}$ as following:

$$
s_{b}(j, i)=\frac{q_{b}(j, i)}{\xi_{b}}
$$

Computational formula on length and cross-sectional area of tobacco internodes can be figured out with formulas (4), (5) and (6). It turns out to be formula (7):

$$
\left\{\begin{array}{l}
\beta=\frac{\alpha-1}{\alpha+1} \\
\boldsymbol{b}_{e}=\mathrm{K}_{e}^{1-\beta}
\end{array}\right.
$$

Value of the length and the cross-sectional area could be figured out in formula (7), only if knowing the biomass of internodes in a certain growing stage when morphology parameters of the internode $\beta, \boldsymbol{b}_{\boldsymbol{e}}$ and density $\rho_{\boldsymbol{e}}$ were given. Then, simulation of internodes morphology can be carried out with biomass.

\subsubsection{Morphology of Tobacco Leaf}

What we need from tobacco is leaf. The leaf is not only a place for photosynthesis but also a place to store all kinds of chemical substances which directly decide the quality of tobacco. The area of leaf $j, \boldsymbol{S}_{\boldsymbol{b}}$, in $i^{\text {th }}$ can be figured out in formula (8) with its biomass $\boldsymbol{q}_{\boldsymbol{b}}$.

$$
\left\{\begin{array}{l}
\boldsymbol{l}_{e}(j, i)=\sqrt{\boldsymbol{b}_{e}}\left[\frac{\boldsymbol{q}_{e}(j, i)}{\rho_{e}(j, i)}\right]^{\frac{1+\beta}{2}} \\
\boldsymbol{s}_{e}(j, i)=\sqrt{\frac{1}{b_{e}}}\left[\frac{q_{e}(j, i)}{\rho_{e}(j, i)}\right]^{\frac{1-\beta}{2}}
\end{array}\right.
$$


$\xi_{b}$ : Specific leaf weight, in other words, value of dividing leaf area into leaf fresh weight $\left(\mathrm{g} / \mathrm{cm}^{2}\right)$.

Showing from experimental data, the relationship between leaf length $\boldsymbol{l}_{\boldsymbol{b}}(\mathrm{cm})$ and its fresh weight $\boldsymbol{q}_{\boldsymbol{b}}$ ( $g$ ) can be expressed with formula (9):

$$
l_{b}(j, i)=k_{i} \cdot q_{b}(j, i)^{r}
$$

$\boldsymbol{k}_{\boldsymbol{i}}$ and $\boldsymbol{r}$ in formula (9) are fitting indexes. For that leaf area is always figured out through multiplying a certain parameter $\lambda$ with the product of leaf length and the maximum width of leaf in agronomy, the maximum width of leaf, $\boldsymbol{w}_{\boldsymbol{b}}(\mathrm{cm})$, can be figured out after the leaf area and leaf length being simulated with the following formula:

$$
w_{b}(j, i)=\frac{s_{b}(j, i)}{\lambda \cdot l_{b}(j, i)}
$$

So, the leaf area (Abb. LA), length and the maximum width of this plant can be figured out after the accumulated biomass of leaf in a certain time being simulated if parameters $\xi_{\boldsymbol{b}}, \boldsymbol{k}_{\boldsymbol{i}}, \boldsymbol{r}$ and $\lambda_{\text {were given. }}$

\subsubsection{Ascertaining Parameters}

Parameter in models can be divided into three kinds: parameters being used to describe the growing process of plant, parameters being used to build the internode model and parameters being used in morphology model. Value of Parameters like growing speed, accumulated biomass, cross-sectional area of the internode, the internode length, leaf area, fresh weight of leaf, leaf width, and specific leaf weight can get from experimental data. However, coefficients like fitting index $\boldsymbol{k}_{\boldsymbol{e}}$ and $\alpha$ of the internode morphology, morphology index $\beta$ and $\boldsymbol{b}_{\boldsymbol{e}}$ of the internode, fitting index $\boldsymbol{k}_{\boldsymbol{i}}$ and $\boldsymbol{r}$ of leaf are implicit parameters. Parameters of model are listed as following table 2 . 
Table 2. List of model parameters

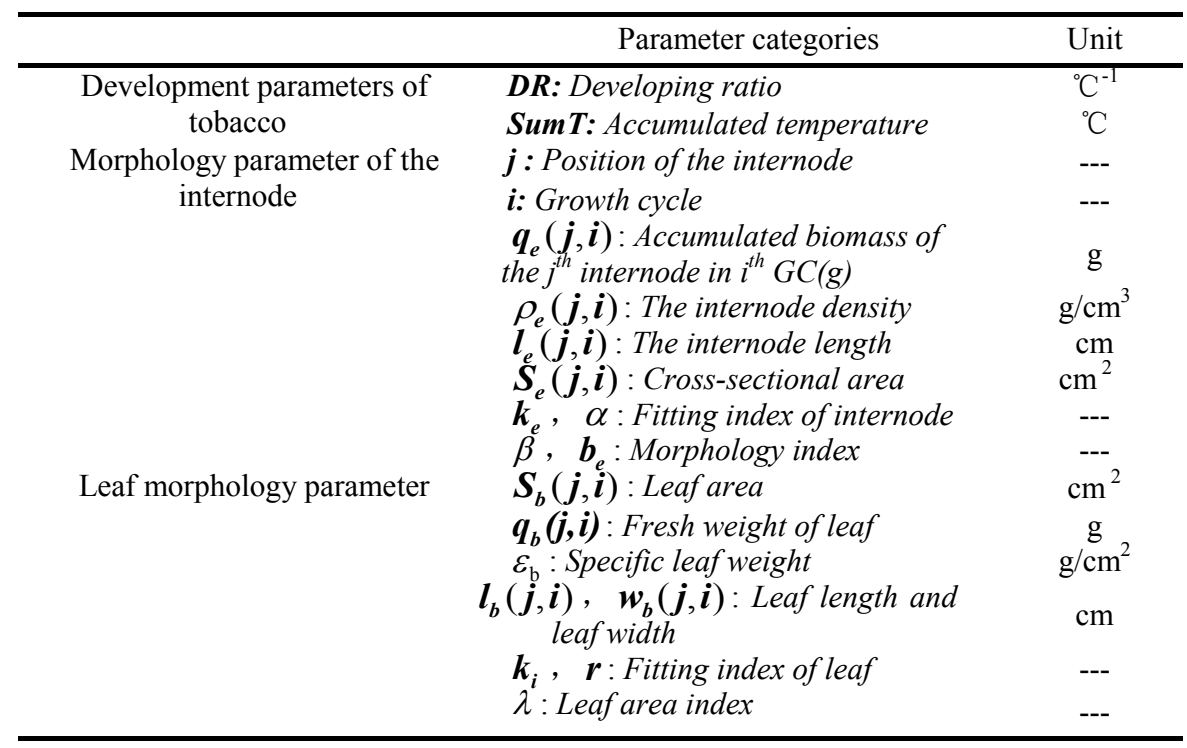

The following Figure 1 is a relation graph between the measured number of tobacco metamer which was defined to be 7 when being transplanted and the accumulated temperature starting from seeding restitution stage.

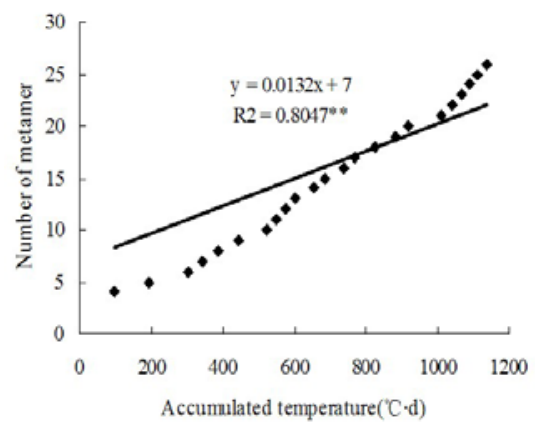

Fig. 1. The relationship between number of tobacco and sum of temperature

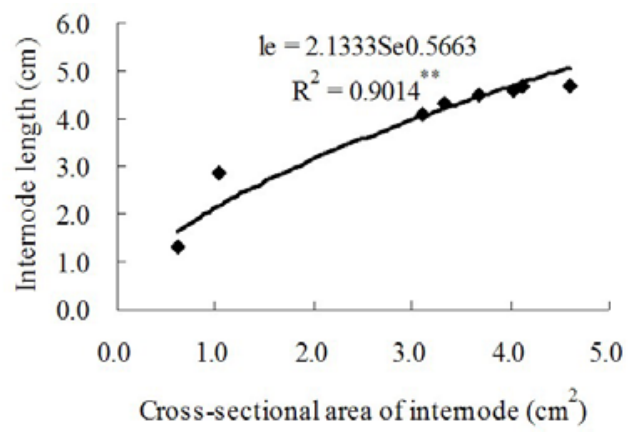

Fig. 2. Relationship between length and cross-sectional area during its elongation $\left(9^{\text {th }}\right.$ internode $)$

As shown in Fig 1, the simulated number of metamer matches the measured number well. The number of GC equals that of metamer, in other words, one metamer could be produced in one GC. Slope in this model is the developing speed of tobacco, 
represented with $\operatorname{DR}\left({ }^{\circ} \mathrm{C}^{-1}\right)$. Meanwhile, a necessary accumulated temperature which is $75.76\left({ }^{\circ} \mathrm{C}^{-1}\right)$ in this model in a GC is represented with the reciprocal of slope. Real length of time in each GC is 2 or 3 days, changing with daily temperature.

Using experimental data, Fitting coefficients $\boldsymbol{k}_{\boldsymbol{e}}, \alpha$ can be figured out with formula (4) and the internode morphology coefficients $\beta$ and $\boldsymbol{b}_{\boldsymbol{e}}$ can also be figured out with formula (5), showed in Fig 3. As shown in fig 3, two peak values of $\boldsymbol{b}_{\boldsymbol{e}}$ appeared in the $5^{\text {th }}$ internode and the $14^{\text {th }}$ internode with the rising of the internode position. The value of $\beta$ grows with the growing of the internode position. For that morphology coefficient in different position of internodes differ, so, the value of $\beta$ and $\boldsymbol{b}_{\boldsymbol{e}}$ in different position should be considered while building the internode morphology model.
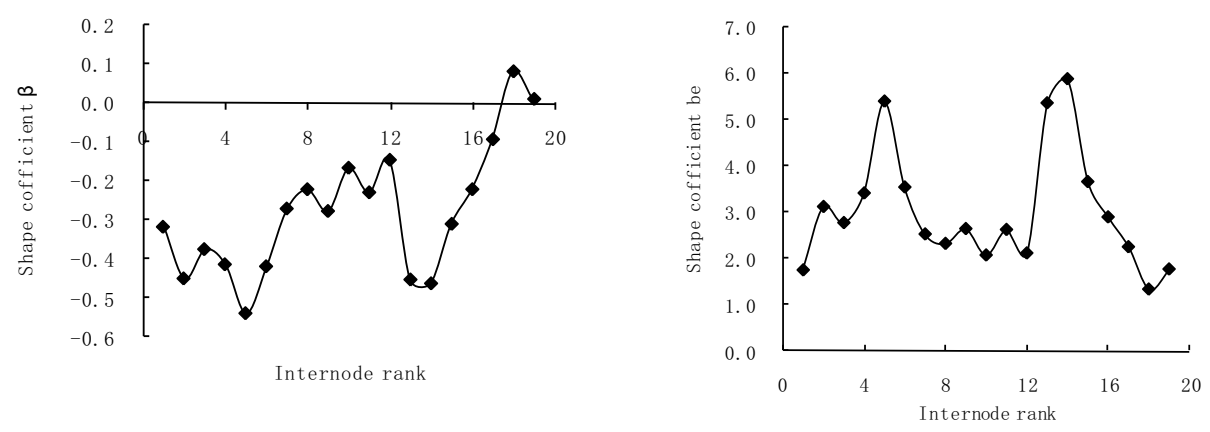

Fig. 3. Internode shape coefficient be and $\beta$ varying with the internode position

The Internode density, showing in fig 4, equals the value that dividing internode volume into measured internode fresh heavy. The internode volume can be acquired by making internode diameter multiply its length. As shown in figure 4, the changing trend of the internode density is different with the position of internode in one GC. The peak value of the third internode density and the $8^{\text {th }}$ internode density come in $12^{\text {th }} \mathrm{GC}$. The internode density grows with rising of the internode position in $16^{\text {th }} \mathrm{GC}$ and $20^{\text {th }} \mathrm{GC}$. The internode density should be selected according to different growing step while simulating the internode morphology for that, in general, the internode density is reducing with the growing of GC.

Through fitting analysis on the leaf fresh weight and its leaf area in different leaf position in different growth period measured in 2006, it appears that specific leaf weight $\varepsilon_{\mathrm{b}}$ :

$\varepsilon_{\mathrm{b}}=0.045\left(\mathrm{r}=0.869^{* *}, \quad n=134\right)$ as shown in figure 5. Leaf length in different position in different GC and its fresh weight can be fitted in formula (9) (Fig. 6). Leaf area of tobacco used to be figured out through multiplying among leaf length, leaf width and leaf area index. Leaf area index $\lambda$ in formula (10) is settled as 0.6345 . 


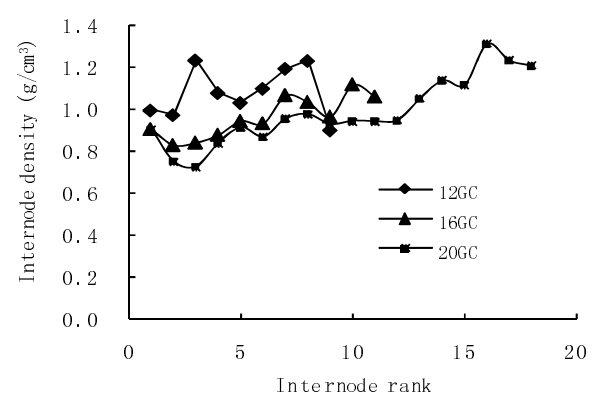

Fig. 4. The density of tobacco internodes

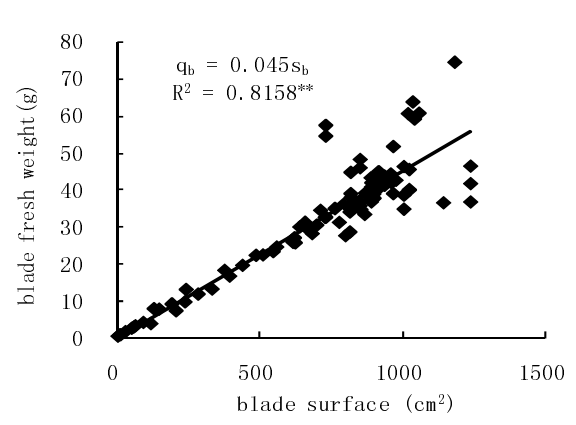

Fig. 5. The relationship between blade fresh weight and surface

\section{Results and Analysis}

In purpose of testing the simulation precision of model on metamer number of tobacco, the predicted results of model was tested with experimental data measured in 2007. The number of metamer was predicted with the help of formula (2) and the accumulated temperature which was measured after being transplanted in 2007. As shown in figure 7, correlation coefficient between the simulated value and actual value reached to 0.992( $\mathrm{n}=23$ ) which comes up to a significant leave. Meanwhile, RMSE between simulated value and actual value is 1.857 which proves them a good uniformity. All tests above prove that it is feasible to simulate the metamer number of tobacco with model.

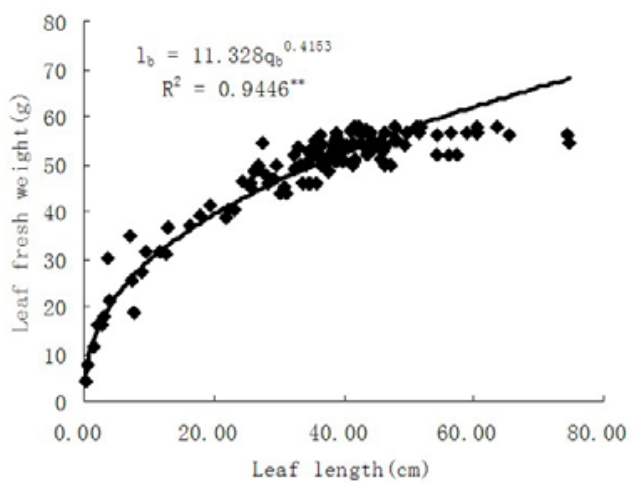

Fig. 6. Relationship between leaf length and its fresh weight

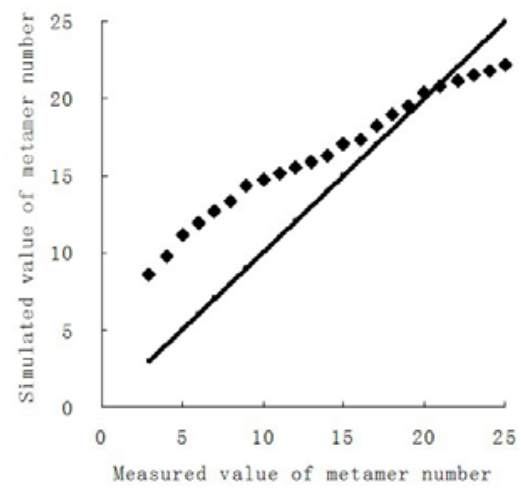

Fig. 7. Comparison between simulated value and mesaured value of metamer number 
Predicted results with models can be tested with experimental data measured in 2007. Taking the $12^{\text {th }}$ and $20^{\text {th }} \mathrm{GC}$ for example, in the $12^{\text {th }} \mathrm{GC}$, correlation coefficients between measured values and simulated values of the internode diameter, the internode length, leaf area and leaf length are $0.997,0.931,0.997,0.992$, all of which come up to a very significant leave $(\mathrm{n}=10)$. RMSE between simulated value and measured value of them are $0.045 \mathrm{~cm}, 2.213 \mathrm{~cm}, 20.570 \mathrm{~cm}^{2}, 1.828 \mathrm{~cm}$. In the $20^{\text {th }} \mathrm{GC}$, correlation coefficients between measured values and simulated values of the internode diameter, the internode length, leaf area and leaf length are 0.994, 0.735, 0.990, 0.949, all of which come up to a very significant leave $(\mathrm{n}=19)$. RMSE between simulated value and measured value of them are $0.040 \mathrm{~cm}, 4.828 \mathrm{~cm}, 40.141 \mathrm{~cm}^{2}$ and $4.039 \mathrm{~cm} .1: 1$ relation schema (Fig8 \& Fig9) between measured value and simulated value of the internode diameter, the internode length, leaf area, leaf length in $12^{\text {th }}$ and $20^{\text {th }} \mathrm{GC}$ show that simulated value from the dynamic model of tobacco growth matches the measured value well.
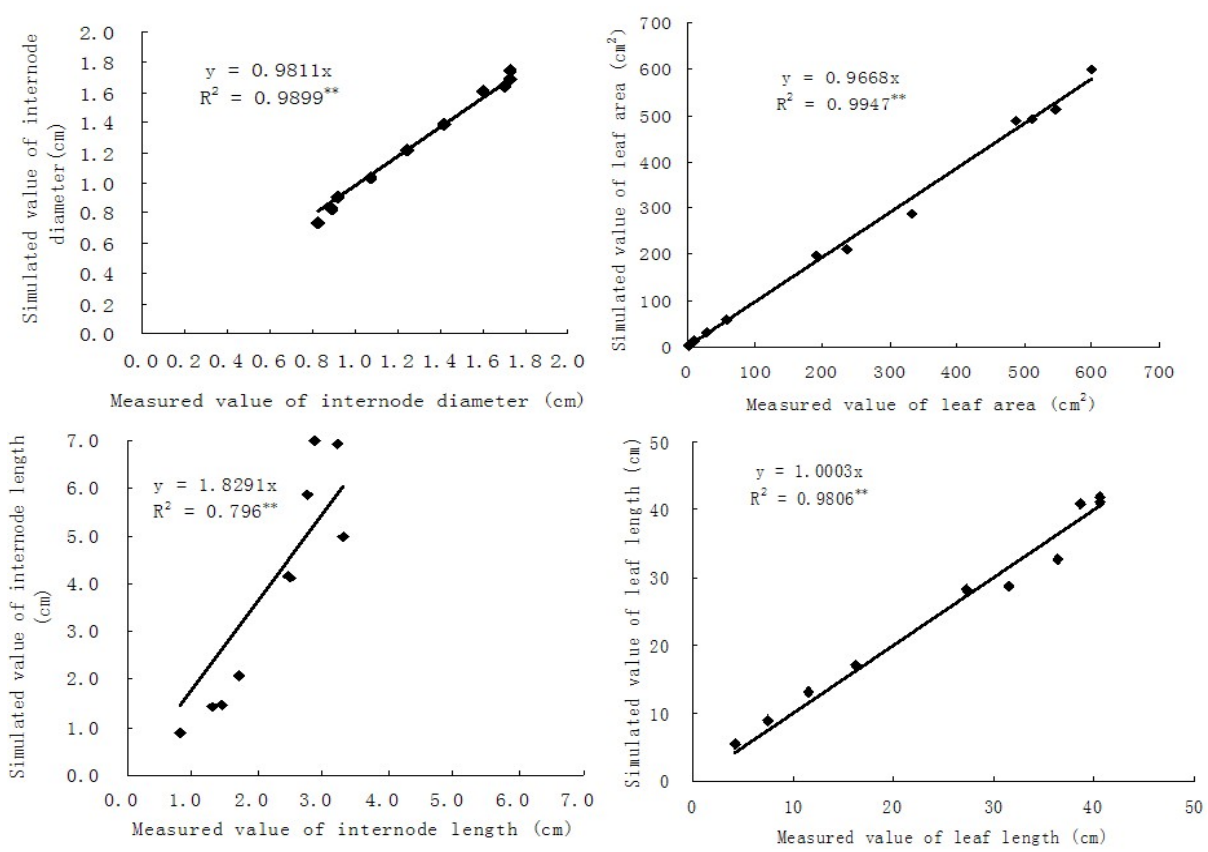

Fig. 8. Comparison between simulated value and measured value in the 12 th GC 

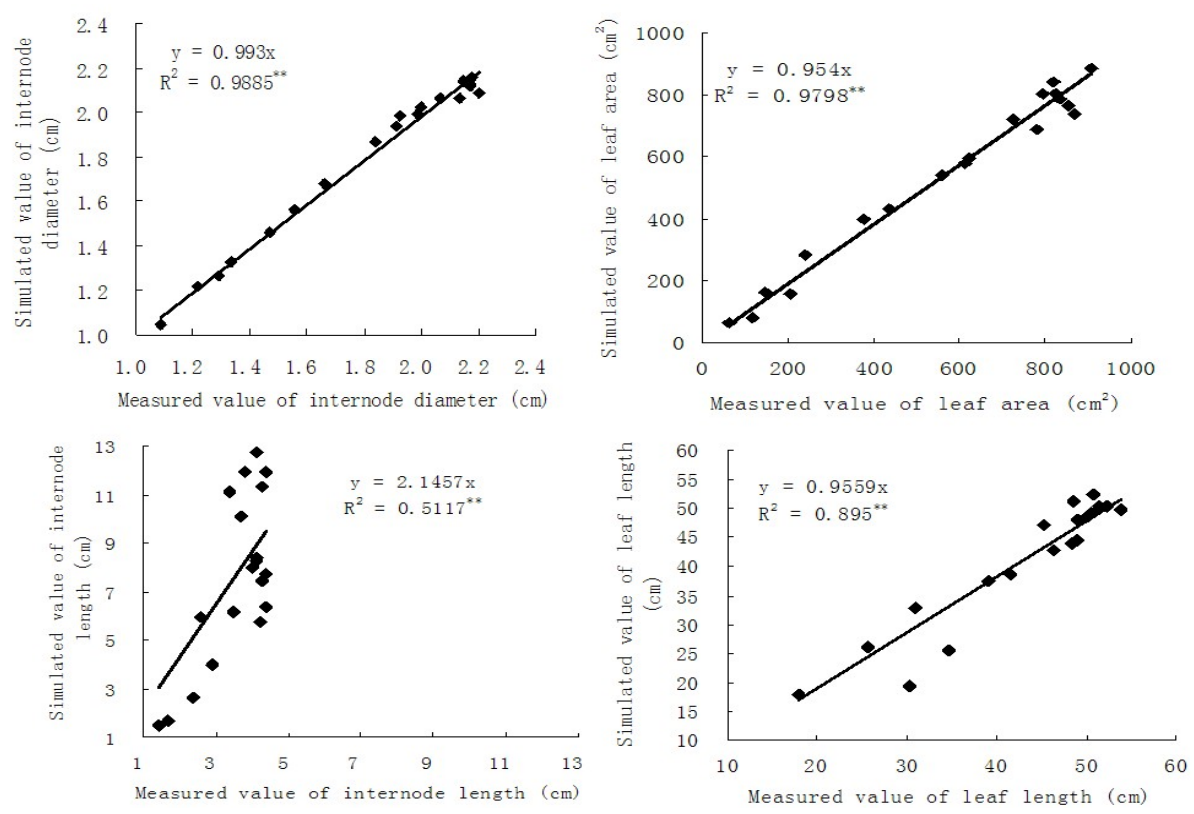

Fig. 9. Comparison between simulated value and measured value in the $20^{\text {th }} \mathrm{GC}$

\section{Conclusions and Discussion}

The essential basis while building digital plant will be plant growing, structure simulation of plant morphology and union of the both. Interrelation between changing of above-ground organ morphology and GC during the growing process of tobacco was generally researched in this paper. Besides, basing on biomass-morphology relationship of tobacco organ, dynamic model on organ morphology was also built in this paper. It turns out that the model can express biological method well and that there is a high degree of uniformity between simulated results and measured values. They have made the model usable.

Growth period model of tobacco is a factorial index model which is using Rice Clock Model for reference and basing on mechanism of tobacco growing and to express growth process of tobacco [30]. Virtual growth system of tobacco, coupled with dynamic organ model and growth period model, will be a new research direction in the next step. The system is necessary while digitizing the tobacco growth. Information on tobacco growth in different stage can be obtained from the system only if the agriculture technician input few certain parameters of growing environment. With that information, cultivating and control technology, fertilizer rate in necessary and so on will be guided well.

Preparing for building the morphology model of above-ground organ of tobacco, the simulation model which based on the model of physiological and ecological process of tobacco, under the control of outside environment, like temperature, was created in this paper. Taking the spatial angle change during the period of tobacco growth into 
consideration while researching and analyzing the dynamic change of tobacco morphology can comprehensively display the dynamic change information of tobacco, and this will be a research direction in the future. At last, that the simulation of the plant internodes morphology is not precise enough, caused by a low sampling rate, should be improved and perfected.

\section{References}

1. Ulam, S.: On some mathematical properties connected with patterns of growth of figures. In: Proceedings of Symposia on Applied Mathematics, pp. 215-224. American Mathematical Society (1962)

2. Cohen, D.: Computer simulation of biological pattern generation processes. Nature 216, 246-248 (1967)

3. Lindenmayer, A.: Mathematical models for cellular interactions in development. J. Theor. Biol. 18, 280-315 (1968)

4. Hunt, R.: Plant growth analysis: the rationale behind the use of the fitted mathematical function. Ann. Bot. 43, 245-249 (1979)

5. de Reffye, P., Fourcaud, T., Blaise, F., et al.: A functional model of tree growth and tree architecture. Silva Fennica 31, 297-311 (1997)

6. de Reffye, P., Houllier, F.: Modeling plant growth and architecture: Some recent advances and applications to agronomy and forestry. Current Science 73, 984-992 (1997)

7. Prusinkiewicz, P., Lindenmayer, A., Hanan, J.: Developmental models of herbaceous plants for computer imagery purpose. Computer Graphics 22(4), 141-150 (1988)

8. Mech, R., Prusinkiewicz, P.: Visual models of plants interacting with their environment. Computer Graphics 30(3), 397-410 (1996)

9. Prusinkiewicz, P.: A look at the visual modeling of plant using L-systems. Agronomie 19, 211-224 (1990)

10. Prusinkiewicz, P., Hammel, M., Mjolsness, E.: Animation of plant development. Computer Graphics 27(3), 351-360 (1993)

11. Room, P.M., Hanan, J.S., Prusinkiewicz, P.: Virtual plants: New perspectives for ecologists, pathologists and agricultural scientists. Trends in Plant Science (1), 33-38 (1996)

12. Kurth, W.: Growth Grammar Interpreter GROGEA2.4: A Software tool for the 3 -dimensional interpretations of stochastic, sensitive growth grammars in the context of plant modeling. In: Introduction and Reference Manual. Universitat gottingen, Gottingen (1994)

13. de Reffye, P., Hu, B.-G.: Relevant qualitative and quantitative choices for building an efficient dynamic plant growth model: GreenLab case. In: Hu, B.-G., Jaeger, M. (eds.) Plant Growth Modeling and Applications, pp. 87-107. Tsinghua University Press, Beijing (2003)

14. Guo, Y., de Reffye, P., Song, Y.H., et al.: Modeling of biomass acquisition and partitioning in the architecture of sunflower. In: Hu, B.-G., Jaeger, M. (eds.) Plant Growth Modeling and Applications, pp. 271-284. Tsinghua University Press, Beijing (2003)

15. Yan, H.P., Kang, M.Z., de Reffye, P., Dingkuhn, M.: A dynamic, architectural plant model simulating resource-dependent growth. Ann. Bot. 93, 591-602 (2004)

16. de Beffye, P., Yan, H.P., Leroux, J., et al.: Study on plant growth behaviors simulated by the function-structural plant model-Greenlab. In: Plant Growth Modeling and Applications Proceedings, pp. 118-128 (2003)

17. Zhan, Z., Wang, Y., de Reffye, P., et al.: Morphological Architecture-Based Growth Model of Winter Wheat. Transaction of the CSAE 17(5), 6-10 (2001) 
18. Song, Y.-H., Guo, Y., Li, B.-G., et al.: Virtual maize model II. Plant morphological constructing based on organ biomass accumulation. Acta Ecologica Sinica 23(12), 2579-2586 (2003)

19. Guo, X., Zhao, C., Liu, Y., et al.: Three-dimensional visualization of maize based on growth models. Transaction of the CSAE 23(3), 121-125 (2007)

20. Ivanov, N., Boissard, P., Chapron, M., et al.: Estimation of the height and angles of orientation of the upper leaves in the maize canopy using sterovision. Agronomie 2, 183-194 (1994)

21. Fournier, C., Andrieu, B.: A 3D architectural and process-based model of maize development. Annals of Botany 81(2), 233-250 (1998)

22. Jin, M.-X., Wang, T.-D.: Simulation of Growth and Hydrotropism of Maize Roots. Acta Botanica Sinica 38(5), 384-390 (1996)

23. Ma, Y.-T., Guo, Y., Zhan, Z.-G., Li, B.-G., et al.: Evaluation of the Plant Growth Model GREENLAB-Maize. Acta Agronomica Sinica 32, 956-963 (2006)

24. Guo, Y., Ma, Y.T., Zhan, Z.G., et al.: Parameter optimization and field validation of the functional-structural model GREENLAB for maize. Annals of Botany 97, 217-230 (2006)

25. Ma, X.-M., Yang, J., Xiong, S.-P., et al.: A Model for Simulating Root Morphological Development of Tobacco. Scientia Agricultura Sinica 38(12), 2421-2427 (2005)

26. Ma, X.-M., Xi, L., Xiong, S.-P., et al.: Dynamic changes of morphological parameters of tobacco root in field. Chinese Journal of Applied Ecology 17(3), 356-357 (2006)

27. Qiao, Y., Yu, Z., Driessen, P.M.: Quantification of dry matter accumulation and distribution among different organs of winter wheat. Chinese Journal of Applied Ecology 13(5), 543-546 (2002)

28. Liu, X., Kang, S., Xia, W.: A mathematical model of water stress and light condition effects on cotton dry matter and yield formation. Chinese Journal of Applied Ecology 13(9), 1085-1090 (2002)

29. Yang, J., Wang, Z.: Crop growth simulation model and its application. Chinese Journal of Applied Ecology 10(4), 501-505 (1999)

30. Xiong, S., Ma, X., Shi, Y.-Y., et al.: Study on Dynamic Simulation Model for the Relationship between Growth and Environmental Factors at Different Tobacco Growth and Development Stage. Journal of Henan Agricultural University 39(3), 321-325 (2005) 